\title{
Cutaneous histoplasmosis as a complication after anti-TNF use - Case report*
}

\author{
Gabrielle Aline Zattar ${ }^{1}$ \\ Sadamitsu Nakandakari ${ }^{1}$
}

\author{
Fernanda Cardoso ${ }^{1}$ \\ Cleverson Teixeira Soares ${ }^{1}$
}

DOI: http:/ / dx.doi.org/10.1590/abd1806-4841.20153545

\begin{abstract}
A bstract: Anti-TNF agents are effective in the treatment of psoriasis. However, they render individuals more susceptible to infections. We report an atypical case of histoplasmosis in an immunosuppressed patient due to antiTNF therapy. A patient who used anti-TNF for the treatment of psoriasis had had a lesion on the right eyebrow since discontinuation of the medication. The diagnostic hypothesis was basal cell carcinoma, but the histopathological examination was compatible with histoplasmosis.
\end{abstract}

Keywords: Histoplasmosis; Immunosuppression; Immunosuppressive agents; Tumor necrosis factor-alpha

\section{INTRODUCTION}

Tumor necrosis factor (TNF)-neutralizing agents are effective in treating various inflammatory conditions in which this cytokine is considered to play an important role. In dermatology it is used to treat psoriasis. ${ }^{1}$ TNF is essential for the formation and maintenance of granulomas, which are important components of host defense against intracellular pathogens. ${ }^{2,3}$ Anti-TNF agents inhibit the proliferation of T-cells and alter Th1 immune response, increasing individuals' susceptibility to infections. There are currently three anti-TNF agents available for use in clinical practice: Infliximab and adalimumab are monoclonal anti-TNF- $\alpha$ antibodies and etanercept is a bivalent soluble TNF receptor (fusion protein).

Histoplasmosis is a systemic infection caused by the dimorphic fungus Histoplasma capsulatum, which transforms into a pathogenic yeast once inhaled. Its incidence has increased after the introduction of anti-TNF. ${ }^{1,4}$ We report an atypical case of histoplasmosis in immunosuppressed patients due to use of anti-TNF.
A 46-year-old male patient had had a lesion on the right eyebrow for three months, ever since adalimumab use had been discontinued. The patient used etanercept for 2 years and 3 months, then adalimumab for 6 months until discontinuation of the treatment. Both drugs had been prescribed for the treatment of 'difficult-to-control' psoriasis. He had no mucosal lesions, lymphadenopathy or systemic symptoms. The patient denied comorbidities as well as contact with birds or bats.

Clinical examination revealed a single papular, erythematous and infiltrated lesion with slight scaling on the surface. The diagnostic hypothesis was basal cell carcinoma (Figures 1 and 2). A biopsy revealed chronic granulomatous dermatitis with areas of caseous necrosis and giant cell reaction. There were small round fungal structures surrounded by a clear halo within the macrophages and the necrotic area, which were morphologically consistent with $\mathrm{H}$ istoplasma capsulatum (Figures 3 to 5). The culture for fungi and mycobacteria gave negative results. Chest radiography showed no changes. Serology was negative for 


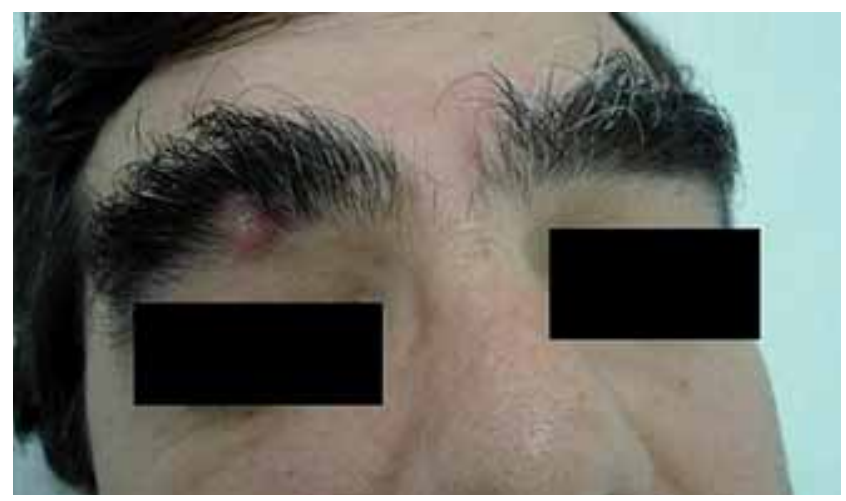

Figure 1: Papular erythematous, infiltrated lesion with slight superficial scaling on the right eyebrow
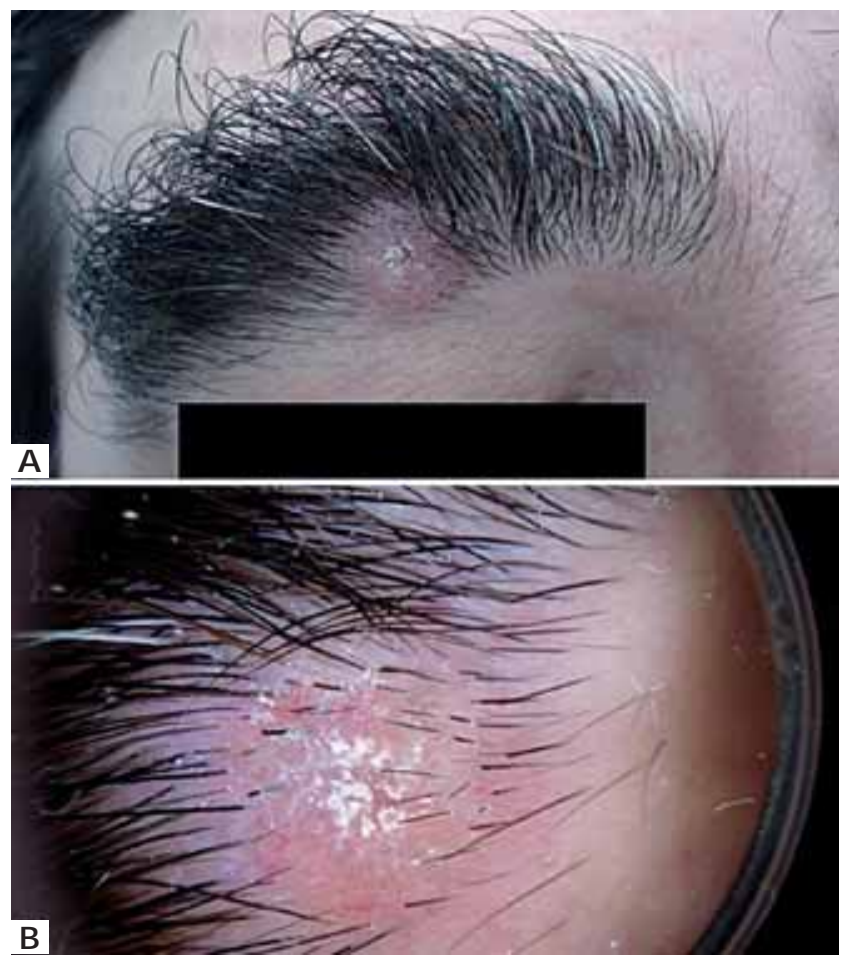

FIgURE 2: A: detail of the lesion simulating basal cell carcinoma. B: Dermoscopy of the lesion shows arborizing telangiectasias on the periphery of the lesion and superficial scaling

paracoccidioidomycosis and serology for histoplasmosis was not performed due to unavailability.

Due to these findings, the patient was treated with itraconazole $400 \mathrm{mg}$ daily for 6 months, with regression of the lesion.

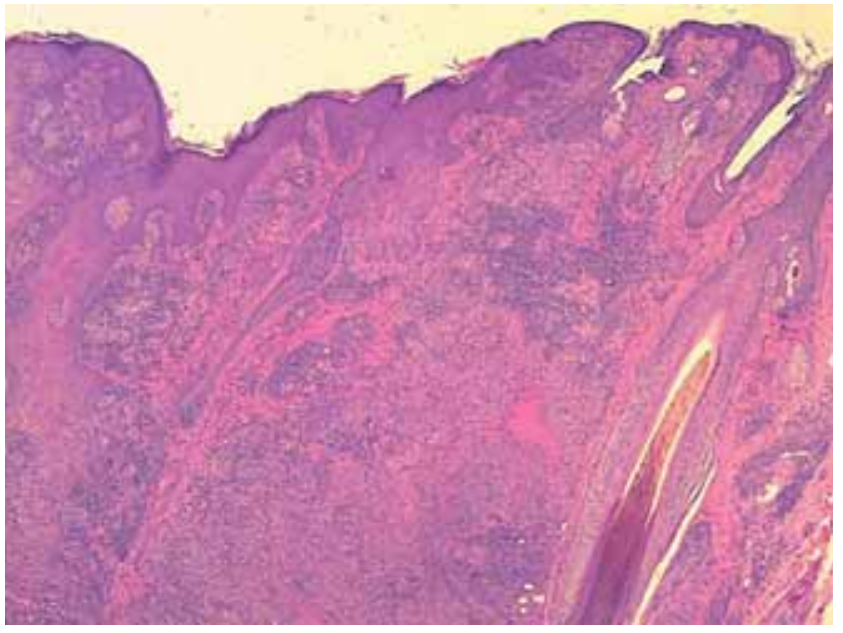

FIgURE 3: Skin with intense pseudocarcinomatous epithelial hyperplasia associated with granulomatous inflammation in the dermis. (HE - 20x)

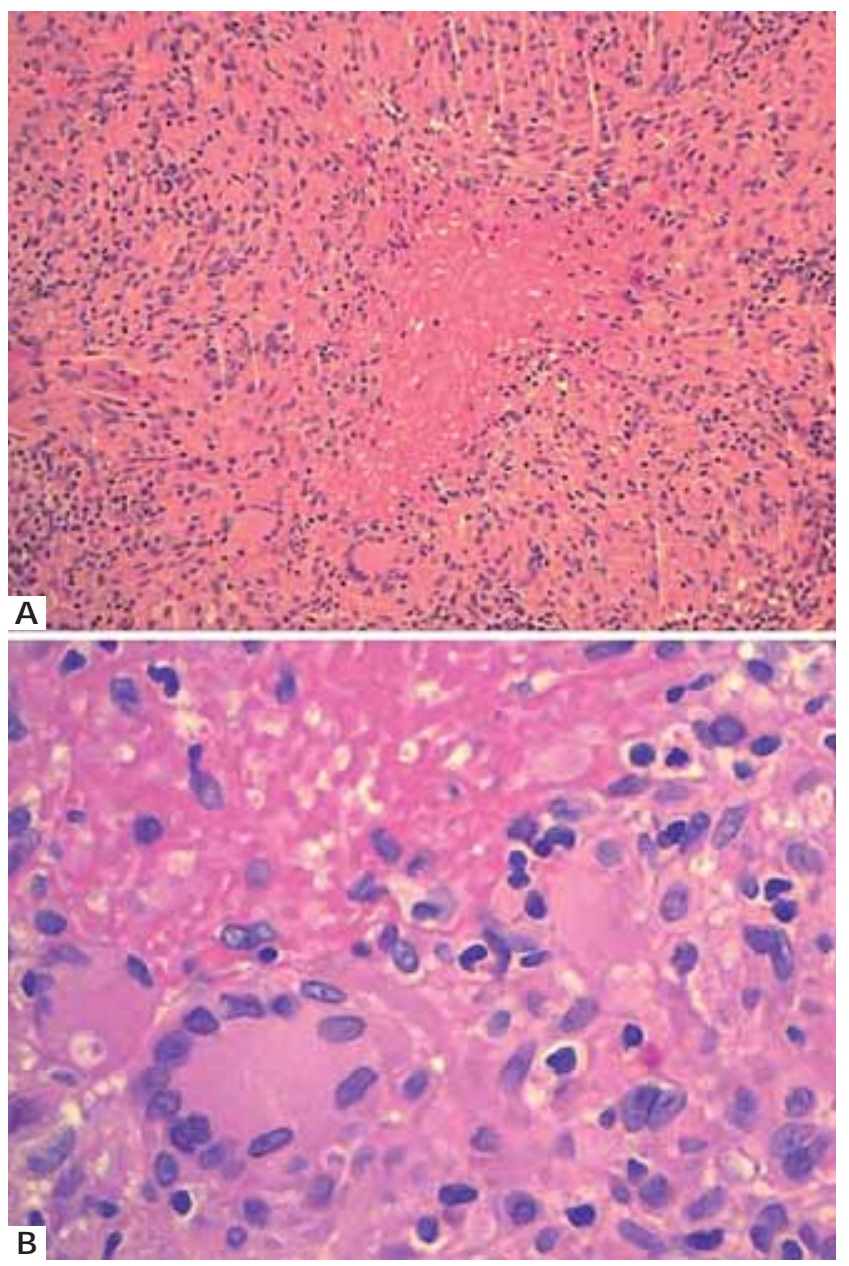

Figure 4: A: Chronic granulomatous inflammation with epithelioid histiocytes, multinucleated giant cells and areas of necrosis (HE - 10x). B: Detailed view - visualization of small round fungal structures surrounded by a clear halo within giant multinucleated cells and the necrotic area (HE - 40x) 

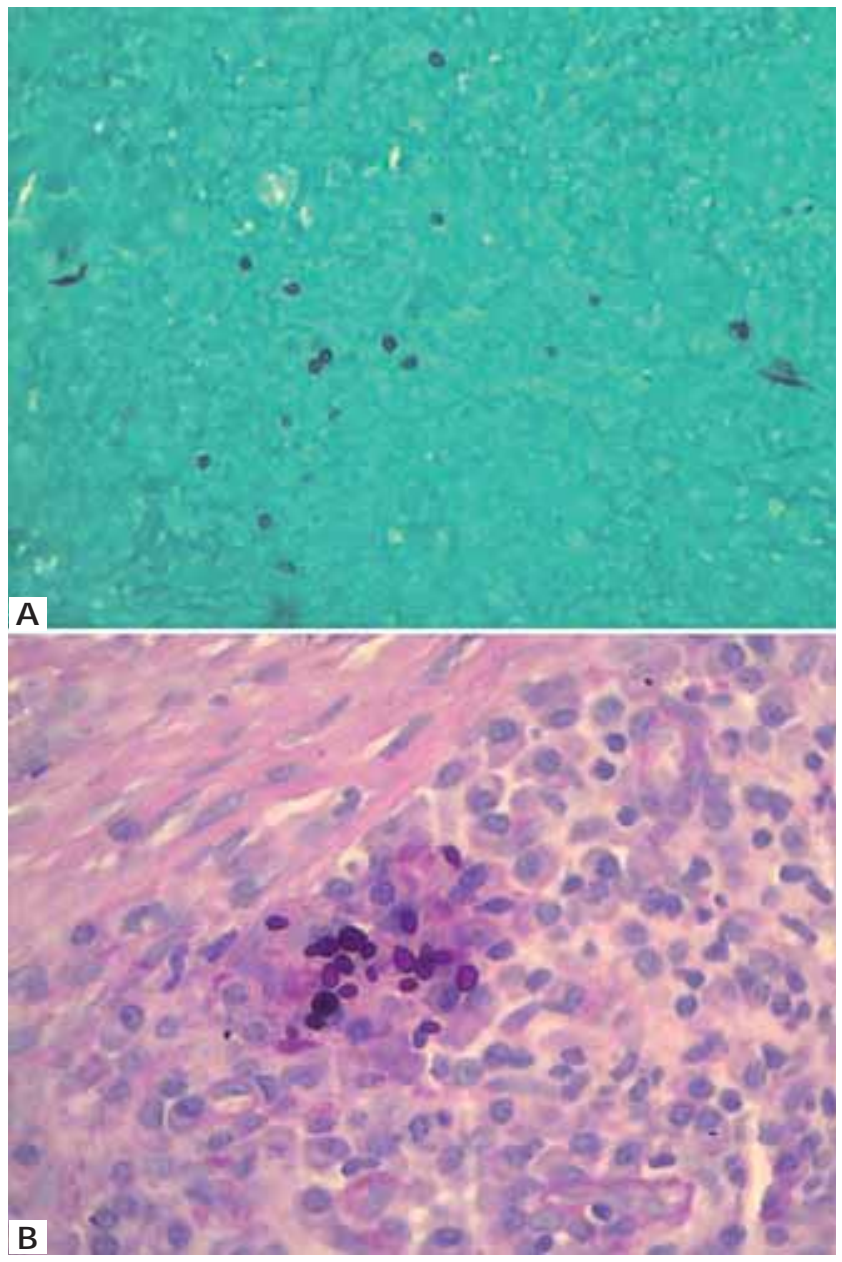

Figure 5: A: Small round fungi morphologically compatible with Histoplasma within granulomas (methenamine silver). B: Small round fungi within macrophages (PAS with diastase)

\section{DISCUSSION}

Most infections by $\mathrm{H}$ istoplasma capsulatum are asymptomatic. ${ }^{5}$ Symptomatic forms include primary and chronic pulmonary histoplasmosis, and localized or disseminated histoplasmosis. ${ }^{6}$ Fungus spores are found in caves, attics, abandoned houses, henneries and the soil. Animal reservoirs are bats, chickens and gregarious birds. ${ }^{5,6}$ The infection is often produced from inhaling spores of the fungus and the host's immune response determines the extent of the disease. A key factor in the development of symptoms is the size of the inoculum. Other factors involved are the virulence of the pathogen, and the host's age and primary underlying diseases. ${ }^{5}$
Histoplasmosis skin lesions are polymorphic. Histopathologically, granulomas are uncommon, while an infiltrate composed of macrophages infected by the microorganism is most commonly seen. 6,7 The diagnosis is made clinically, epidemiologically and through laboratory testing (culture, histopathology and serology). ${ }^{5,6}$

In our case, despite the unusual epidemiology - the patient denied any contact with birds and bats - the histopathological examination was essential for the diagnosis, because it showed fungal structures compatible with Histoplasma capsulatum. In addition, the culture of the lesion fragment for fungus was only performed after removing a significant portion of the fragment for histopathological examination. The shortage of material may have contributed to the negative results.

The main differential diagnoses for these histopathological findings include paracoccidioidomycosis and leishmaniasis. However, Paracoccidioides brasiliensis is a larger fungus that has multiple budding, assuming the aspect of a "rudder wheel"; Leishmania sp. is not stained by silver; and both do not show the typical clear halo described, which essentially excludes these diagnoses. ${ }^{8}$

Immunomodulatory therapy anti-TNF- $\alpha$ agents poses a risk of developing histoplasmosis. ${ }^{9}$ In immunocompromised patients, the infection is often widespread, unlike the case reported here. The occurrence of histoplasmosis in these patients is probably the result of reactivation of latent infection or new exposure (or re-exposure) of the host to the organism. ${ }^{9}$

Most cases found in the literature on the association of histoplasmosis with the use of anti-TNF were patients coming from endemic regions, who had been treated with multiple immunomodulatory agents, just like our case. ${ }^{1,2,9-11}$ Infliximab was the most common anti-TNF agent used. ${ }^{1,2,9-11}$

We emphasize the importance of considering histoplasmosis as a differential diagnosis of cutaneous lesions in immunosuppressed patients. Moreover, patients using these medications should be counseled to avoid activities that increase the risk of exposure to the pathogen, such as exploring caves and cleaning bird droppings.] 


\section{REFERENCES}

1. Lee JH, Slifman NR, Gershon SK, Edwards ET, Schwieterman WD, Siegel JN, et al. Life-threatening histoplasmosis complicating immunotherapy with tumor necrosis factor $\alpha$ antagonists infliximab and etanercept. Arthritis Rheum. 2002:46:2565-70.

2. Bakleh M, Tleyjeh I, Matteson EL, Osmon DR, Berbari EF. Infectious complications of tumor necrosis factor-alpha antagonists. Int J Dermatol. 2005;44:443-8.

3. Wallis RS, Broder MS, Wong JY, Hanson ME, Beenhouwer DO. Granulomatous infectious diseases associated with tumor necrosis factor antagonists. Clin Infect Dis. 2004;38:1261-5.

4. Deepe GS Jr, Gibbons RS. T cells require tumor necrosis factor- $\alpha$ to provide protective immunity in mice infected with Histoplasma capsulatum. J Infect Dis. 2006;193:322-30.

5. Brasil. Ministério da Saúde. Secretaria de Vigilância em Saúde. Departamento de Vigilância Epidemiológica. Doenças infecciosas e parasitárias: guia de bolso. 8. ed. rev. Brasília: Ministério da Saúde; 2010. 448 p. : il. - (Serie B. Textos Básicos de Saúde).

6. Azulay RD, Azulay DR, Azulay-Abulafia L. Dermatologia. 6. ed. Rio de Janeiro: Guanabara Koogan; 2013.

7. Chang P, Rodas C. Skin lesions in histoplasmosis. Clin Dermatol. 2012;30:592-8.

8. Vidyanath S, Shameena P, Sudha S, Nair RG. Disseminated histoplasmosis with oral and cutaneous manifestations. J Oral Maxillofac Pathol. 2013;17:139-42.

9. Olson TC, Bongartz T, Crowson CS, Roberts GD, Orenstein R, Matteson EL. Histoplasmosis infection in patients with rheumatoid arthritis, 1998-2009. BMC Infect Dis. 2011:11:145.

10. Tsiodras S, Samonis G, Boumpas DT, Kontoyiannis DP. Fungal infections complicating tumor necrosis factor alpha blockade therapy. Mayo Clin Proc. 2008;83:181-94

11. Wood KL, Hage CA, Knox KS, Kleiman MB, Sannuti A, Day RB, et al. Histoplasmosis after treatment with anti-tumor necrosis factor-alpha therapy. Am J Respir Crit Care Med. 2003;167:1279-82.
M AILING ADDRESS:

Gabrielle A line Z attar

Rodovia Comandante João R ibeiro de Barros km 225/226, 17034-971 - Bauru - SP

Brazil

E-mail: gabi.zattar@gmail.com

How to cite this article: Zattar GA, Cardoso F, Nakandakari S, Soares CT. Cutaneous histoplasmosis as a complication after anti-TNF use: a case report. An Bras Dermatol. 2015;90 (3 Suppl 1):S104-7 